\title{
THE RELIABILITY OF AMS RADIOCARBON DATING OF SHELLS FROM CHINA
}

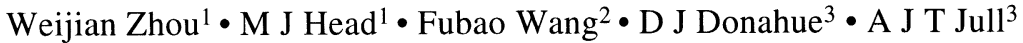

\begin{abstract}
We tested the feasibility of dating freshwater and terrestrial molluscs from the semiarid and arid zone in China, since these types of shell material deposit only aragonite to form their shell structure, and shell integrity can be easily observed using X-ray diffraction. We also tested the possibility of estimating microenvironmental changes from shell $\delta^{13} \mathrm{C}$ values, but variations within shell populations preclude the use of these values as a reliable indicator. Reservoir ages were calculated for living shells of the same species as fossil shells by using their measured ${ }^{14} \mathrm{C}$ ages, which were recalculated using an average value of atmospheric ${ }^{14} \mathrm{C}$ activity for the years spanning their time of collection as the modern standard. The results indicate that freshwater and terrestrial shells are potentially useful as dating material, provided extreme care is taken in their collection and other datable material (in this case wood and pollen) is within the profile to act as a comparison.
\end{abstract}

\section{INTRODUCTION}

Freshwater and terrestrial mollusc shells are likely to have incorporated older limestone-derived bicarbonate into their shell structures. Shells from estuarine, lacustrine or river systems can either have relatively large apparent ages, or be living in equilibrium with the atmosphere, depending on the source and flow rate of the water (Head 1991; Spennemann and Head 1996). Often, the living environment of these shells may be determined by $\delta^{13} \mathrm{C}$ values, though if the source of the water is variable or mixed, these values may provide little information. Land snails ingest calcium carbonate, which is digested to form $\mathrm{CO}_{2}$ and subsequently incorporated into their shells (Goodfriend 1987).

Freshwater and terrestrial species produce shells consisting of aragonite with a coating of calcite if recrystallization has occurred. The aragonite and calcite can be distinguished visually and separated using a small drill and grinding wheel, or with selective use of a dilute $\mathrm{HCl}$ solution. The aragonite can be verified by X-ray diffraction or Fourier transform infrared spectrometry. If postdepositional recrystallization has occurred, calcite is the favored form of the reworked calcium carbonate.

Snail shell fossils are quite common within loess-palaeosol sequences throughout the Loess Plateau in China. Different combinations of species have been found in different layers, reflecting slightly different natural environments. The snails can be regarded as a type of indicator for the paleoenvironments in which the loess-paleosol sequences were formed (Liu et al. 1985). Species reflecting warmer, wetter conditions are predominant in paleosols, but these gradually decrease in number, giving way to drought-enduring and cold-resistant Cathaica assemblages in loess. In the paleosol sequences, fossil snail species are similar to the species assemblages currently found. One of the predominant species is Metodontia (Liu et al. 1985).

\section{SAMPLE TREATMENT AND METHODS}

X-ray diffraction patterns were run on shell samples at both Nanjing Normal University and the University of Arizona in order to determine the presence of calcite in the shell crystalline structure. Calcite would indicate either secondary deposition or recrystallization, since both lacustrine and terrestrial shells are normally composed mainly of aragonite. The shells were cleaned for 30 min with distilled water in an ultrasonic bath, then dried in an oven at approximately $60^{\circ} \mathrm{C}$. The shells were then treated with phosphoric acid for 5-7 min, rinsed with water several times, and dried in an oven again at about $60^{\circ} \mathrm{C}$. Portions of each shell sample were then treated with phosphoric acid in an acid

\footnotetext{
${ }^{1}$ State Key Laboratory of Loess and Quaternary Geology, Chinese Academy of Sciences, PO Box 17, Xi'an 710054, China ${ }^{2}$ Department of Geo and Ocean Sciences, Nanjing University, 22 Hankou Road, Nanjing 210093, China

${ }^{3}$ NSF AMS Facility, University of Arizona, PO Box 210081, Tucson, Arizona 85721 USA
} 
evolution vessel to produce $\mathrm{CO}_{2}$, which was reduced to graphite for ${ }^{14} \mathrm{C}$ AMS determinations (Slota et al. 1987). This work was carried out at the NSF AMS Facility at the University of Arizona. A portion of the $\mathrm{CO}_{2}$ from each sample was taken for $\delta^{13} \mathrm{C}$ determinations.

In 1993, live samples were collected from each of the sites involved in this study. The molluscs were boiled in water to facilitate the removal of flesh and outer protein material. They were then ovendried, treated with hydrogen peroxide to remove the bulk of organic material, rinsed with distilled water and dried again. Further treatment was as described for the fossil samples. X-ray diffraction patterns run on powdered portions of all the modern mollusc samples indicated that these shells consisted of $100 \%$ aragonite. Since nuclear explosions have increased the atmospheric ${ }^{14} \mathrm{C}$ concentration above natural levels, we calculated a percent Modern value of $1.1404 \pm 0.0072$ with respect to the ${ }^{14} \mathrm{C}$ modern standard, and this value was used instead of the normal modern standard to calculate an apparent age for the living shells. These apparent ages were then used to correct the conventional ${ }^{14} \mathrm{C}$ accelerator mass spectrometry (AMS) ages (Stuiver and Polach 1977) obtained for the fossil shell samples.

\section{RESULTS AND DISCUSSION}

In the present study we try to estimate the validity of ages obtained from freshwater and terrestrial snail shells in 4 ways: 1) by measuring and correlating the stable carbon isotopic composition of shells formed under different environmental conditions; 2) by measuring the ${ }^{14} \mathrm{C}$ composition of contemporary freshwater and terrestrial shell samples to gain an appreciation of the reservoir effect associated with the specific species of shells studied; 3 ) by using X-ray diffraction data to differentiate calcite from aragonite; and 4) by comparing ${ }^{14} \mathrm{C}$ ages of shells with those obtained from other datable materials (in this case, wood and pollen) collected from the same stratigraphic horizons. From the ${ }^{14} \mathrm{C}$ measurements of living shells collected in 1993 we calculated a modern standard using Southern Hemisphere monthly atmospheric ${ }^{14} \mathrm{C}$ concentration data for the period $1990-1993$ (the average age of most of these shells is about $3 \mathrm{yr}$ ) kindly provided by JC Vogel, Quaternary Dating Research Unit, EMATEK-CSIR, Pretoria. Because Northern Hemisphere atmospheric data from the collection area are inadequate, only the Southern Hemisphere data were used. The consequent age differences would be no more than $40 \mathrm{yr}$, which is quite adequate for this type of study. From the living shell sample collected in 1993, an apparent age of $1260 \pm 70 \mathrm{BP}$ was calculated. This apparent age was then subtracted from the measured ${ }^{14} \mathrm{C}$ ages of the shells to give reservoir-corrected ${ }^{14} \mathrm{C}$ ages, which were then assessed as semiquantitative estimates by comparison with other dated material or by stratigraphic correlation.

\section{Freshwater Shells}

A series of freshwater mollusc samples (Radix spp.) were collected from cores taken from lake sediments in Ang Ren Lake, Tibet $\left(29^{\circ} 25^{\prime} \mathrm{N}, 87^{\circ} 20^{\prime} \mathrm{E}\right)$. The sediments cover a range of $464 \mathrm{~cm}$ (Fig. 1), with a coarse gravel deposit overlying the top. From $0 \mathrm{~cm}$ down to $394 \mathrm{~cm}$ are layers of light gray to white diatomites containing shells. From $394 \mathrm{~cm}$ to $404 \mathrm{~cm}$ is a layer of peaty material containing wood branches. Below this is a layer of light yellow diatomite. X-ray diffraction studies on the mollusc samples indicated that these shells consisted only of aragonite. Table 1 shows $\delta^{13} \mathrm{C}$ values and ${ }^{14} \mathrm{C}$ AMS results, together with the calculated reservoir-corrected ages.

To further evaluate the shell chronology, we dated cellulose extracted from wood branches collected at a depth of $398 \mathrm{~cm}$ (AA-16360, $9920 \pm 80 \mathrm{BP}$ ). This age fits well with the onset of warmer conditions after the end of the Younger Dryas cold period. The wood cellulose age is significantly younger than the bottom shell AMS ${ }^{14} \mathrm{C}$ age (AA-16818, $392.6 \mathrm{~cm}, 10,530 \pm 85 \mathrm{BP}$ ) by about $610{ }^{14} \mathrm{C}$ yr. It is also older than the shell reservoir-corrected age $(9270 \pm 100 \mathrm{BP})$ by $650{ }^{14} \mathrm{C}$ yr, indicating that the reservoir correction value used for this shell date may not be a true indicator of the 


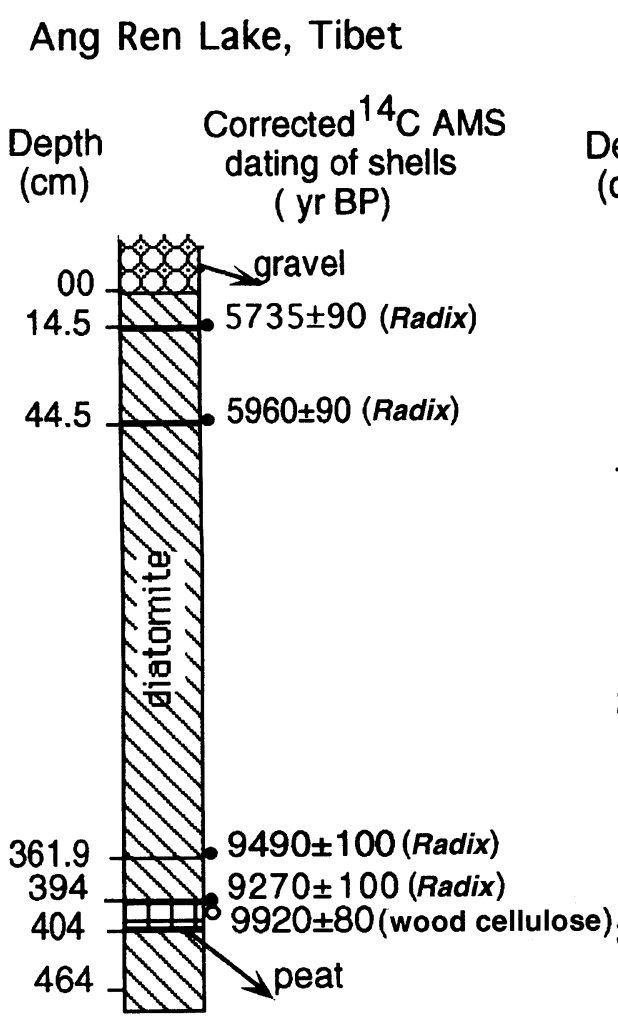

A
Liang Cun, Shaanxi
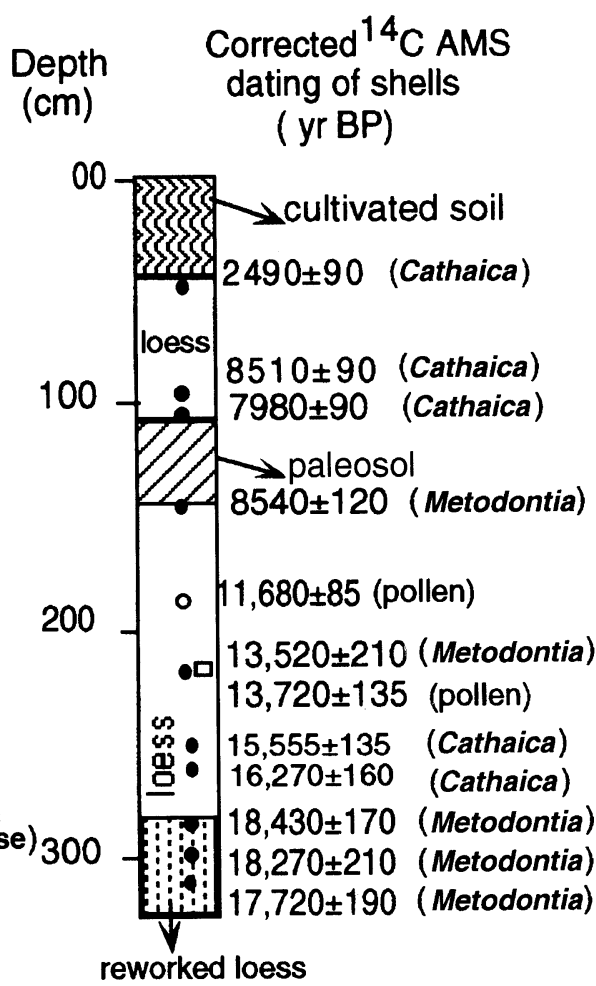

B

Figure 1 Stratigraphic columns of the selected localities. A. Diatomite profile of Ang Ren Lake, Tibet. B. Loesspaleosol sequence at Liang Cun. The symbols $\bullet, \mathbf{O}$, and $\mathbf{\square}$ represent shell, wood and pollen samples, respectively, as control points. Shell sample ages have been corrected using the reservoir-corrected modern shell age. The corrected AMS ${ }^{14} \mathrm{C}$ ages on the right side of $1 \mathrm{~B}$ are considered to be the most reliable ages for the sequence.

Table 1 AMS dating of freshwater shells from Ang Ren Lake, Tibet

\begin{tabular}{lccrc}
\hline Lab code $^{\mathrm{a}}$ & $\begin{array}{c}\text { Depth } \\
(\mathrm{cm})\end{array}$ & $\begin{array}{c}\delta^{13} \mathrm{C} \\
(\%)\end{array}$ & \multicolumn{1}{c}{$\begin{array}{c}{ }^{14} \mathrm{C} \text { age } \\
(\mathrm{yr} \mathrm{BP})\end{array}$} & $\begin{array}{c}\text { Reservoir- } \\
\text { corrected age }\end{array}$ \\
\hline AA-16852 & Live & -1.3 & $205 \pm 50$ & $1260 \pm 70$ \\
AA-16816 & 14 & -0.5 & $6995 \pm 75$ & $5735 \pm 90$ \\
AA-16817 & 43.7 & 0 & $7220 \pm 70$ & $5960 \pm 90$ \\
AA-16819 & 361.4 & -4.2 & $10,750 \pm 85$ & $9490 \pm 100$ \\
AA-16818 & 392.6 & -1.8 & $10,530 \pm 85$ & $9270 \pm 100$ \\
AA-16360 & 398 & -27.4 & $9920 \pm 80$ & \\
\hline
\end{tabular}

aAA is the laboratory code of the NSF AMS Facility, University of Arizona.

bIndicates the living shell sample collected to calculate a reservoir age to be subtracted from the other shell ages.

'Indicates the wood cellulose sample used as a check for the shell ages. 
effect associated with this sample. The best explanation for this possible change in reservoir conditions is to postulate a relatively freshwater phase occurring after peat deposition, indicating a relatively gradual (ca. $100 \mathrm{yr}$ ) change from warm-wet to cold-wet to cold-dry conditions. A reservoir correction of about $700{ }^{14} \mathrm{C}$ yr would be indicated if the wood cellulose age is taken as a marker.

All $\delta^{13} \mathrm{C}$ values for the shell samples are similar, except for the shell sample collected at $361.9 \mathrm{~cm}$. The value of $-4.2 \%$ o differs significantly from the rest and could indicate continuance of this freshwater phase. However, an older reservoir correction would be more feasible to fit the age of the sample into the stratigraphic sequence. A hypothetical rate of deposition versus age plot was calculated using the wood cellulose age and the top shell reservoir-corrected age at $14 \mathrm{~cm}$ (AA-16816, $5735 \pm 90 \mathrm{BP}$ ). Figure 2 shows the correlation between this plot and the reservoir-corrected ages of the other 2 shells. The only reservoir-corrected shell age that does not fit the sequence is that for sample AA-16818, which we have already associated with a freshwater phase directly above the peat layer.

The gravel layer can be associated with colder, drier conditions associated with periodic flooding. A hypothetical age of about $5500 \mathrm{BP}$ fits in with the concept of cold conditions beginning at about 5500 $\mathrm{BP}$ elsewhere. The peat layer can be associated with the onset of warmer, wetter conditions after the Younger Dryas cold period. The wood cellulose age $9920 \pm 80 \mathrm{BP}$ fits the concept quite well (Table 1).

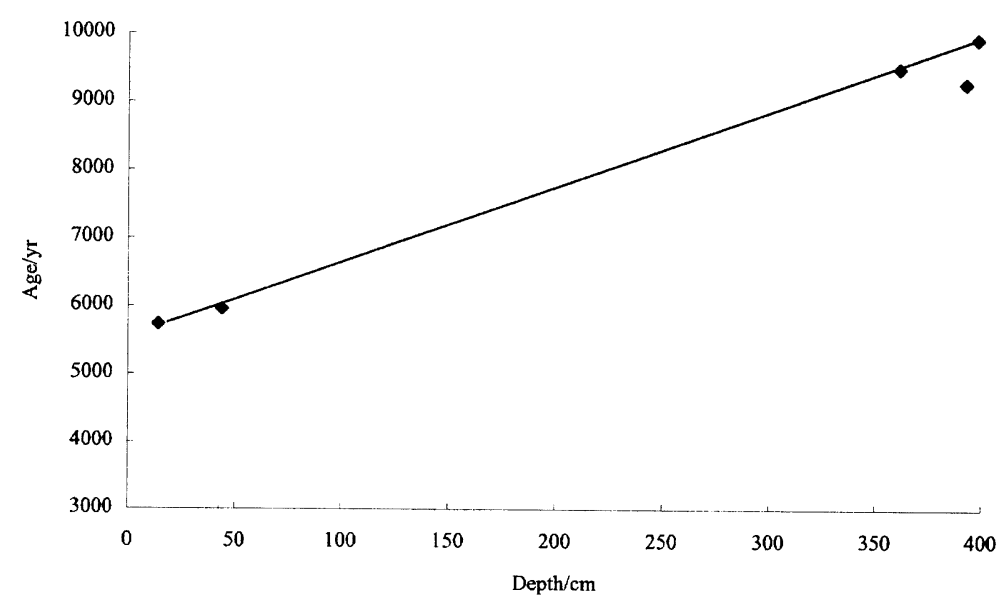

Figure 2 Ang Ren Lake, Tibet. A plot of reservoir-corrected AMS ${ }^{14} \mathrm{C}$ shell ages vs. depth compared with a hypothetical rate of deposition plot using a wood cellulose date from $398 \mathrm{~cm}$ and the corrected shell date at $14 \mathrm{~cm}$ as control points. We can see that all of the reservoir-corrected shell ages fall along the line except for sample AA-16818. This shows that the reservoir-corrected ages used for this profile are acceptable.

\section{Terrestrial Shells}

The Liang Cun loess-paleosol sequence profile is located at the second terrace of the north bank of the Bahe River, $40 \mathrm{~km}$ north of Xi' an City $\left(34^{\circ} 28^{\prime} \mathrm{N}, 108^{\circ} 57^{\prime} \mathrm{E}\right)$, shown in Figure 1B. The profile is $3.3 \mathrm{~m}$ thick and consists of pale yellowish upper Malan Loess, containing snail shells (Cathaica sp.) from $330-140 \mathrm{~cm}$ below the surface. Evidence of slight reworking at around $185-190 \mathrm{~cm}$ and also at $225-$ $230 \mathrm{~cm}$ indicates possible weak paleosol formation. A pale grayish-yellow weak pedogenic paleosol extends from 140-102 cm, a pale yellowish loess deposit from 102-49 cm, and cultivated soil between $49 \mathrm{~cm}$ and the surface. In the loess sections, the Cathaica species of snail shells predominates, while in the weak paleosol sections, the Metodontia species is also present (Liu et al. 1985). 
Twenty fossil shell and 2 paleosol samples were collected for dating, as well as a living shell sample (Cathaica). X-ray diffraction patterns for those shells collected below $140 \mathrm{~cm}$, and $\delta^{13} \mathrm{C}$ values for all shell samples were obtained, together with AMS ${ }^{14} \mathrm{C}$ ages. An apparent age for the living shell sample (aragonite) was calculated as $2680 \pm 60 \mathrm{BP}$. This value was subtracted from the AMS shell ages to give reservoir-corrected ages (Table 2). For this feasibility study we have assumed that since both species of snail shell occupy somewhat similar environments, then the apparent age of the shells would also be similar. The $\delta^{13} \mathrm{C}$ values form 2 distinct groupings, -2.5 to $-3.5 \%$ (Metodontia) and -5.8 to $-9.9 \%$ (Cathaica). All samples whose crystal structure was examined using X-ray diffraction, and have $\delta^{13} \mathrm{C}$ values between -5.8 and $-9.9 \%$ also have calcite present in their crystal structures, except for the living shell sample. Therefore, the ${ }^{14} \mathrm{C}$ ages for these samples may be considered unreliable, though this may not necessarily be the case.

Table $2{ }^{14} \mathrm{C}$ AMS dating of terrestrial shells from the Liang Cun loess-paleosol sequence, Shaanxi Province, China

\begin{tabular}{lcccc}
\hline Lab code & $\begin{array}{c}\text { Depth } \\
(\mathrm{cm})\end{array}$ & $\begin{array}{c}\delta^{13} \mathrm{C} \\
(\%)\end{array}$ & $\begin{array}{c}{ }^{14} \mathrm{C} \text { age } \\
(\mathrm{yr} \mathrm{BP})\end{array}$ & $\begin{array}{c}\text { Reservoir- } \\
\text { corrected age }\end{array}$ \\
\hline AA-16578 & Live & -9.3 & $1625 \pm 50$ & $2680 \pm 60$ \\
AA-12327 & 49 & -7.2 & $5170 \pm 80$ & $2490 \pm 90$ \\
AA-12328 & 62 & -8.5 & $3710 \pm 60$ & $1030 \pm 70$ \\
AA-12329 & 95 & -7.2 & $11,190 \pm 80$ & $8510 \pm 90$ \\
AA-12330 & 102 & -7.8 & $10,660 \pm 80$ & $7980 \pm 90$ \\
AA-12331 & 140 & -3.5 & $11,220 \pm 110$ & $8540 \pm 120$ \\
AA-12332 & 148 & -8.4 & $10,490 \pm 80$ & $7810 \pm 90$ \\
AA-12333 & 158 & -8.3 & $8360 \pm 70$ & $5680 \pm 80$ \\
AA-12334 & 177 & -7.3 & $4770 \pm 60$ & $2090 \pm 70$ \\
AA-12335 & 186 & -7.5 & $13,680 \pm 100$ & $11,000 \pm 110$ \\
AA-12336 & 193 & -8.7 & $2710 \pm 50$ & $30 \pm 60$ \\
AA-12337 & 197 & -9.9 & $12,840 \pm 125$ & $10,160 \pm 130$ \\
AA-12338 & 218 & -5.8 & $11,880 \pm 120$ & $9200 \pm 130$ \\
AA-12339 & 226 & -2.8 & $16,200 \pm 200$ & $13,520 \pm 210$ \\
AA-12340 & 243 & -8.2 & $11,030 \pm 90$ & $8350 \pm 100$ \\
AA-12341 & 252 & -6.0 & $18,950 \pm 150$ & $16,270 \pm 160$ \\
AA-12342 & 262 & -6.0 & $18,235 \pm 125$ & $15,555 \pm 135$ \\
AA-12343 & 267 & -6.8 & $14,480 \pm 130$ & $11,800 \pm 140$ \\
AA-12344 & 290 & -2.8 & $21,110 \pm 160$ & $18,430 \pm 170$ \\
AA-12345 & 300 & -2.5 & $21,400 \pm 200$ & $18,720 \pm 210$ \\
AA-12346 & 310 & -3.3 & $20,400 \pm 185$ & $17,720 \pm 190$ \\
AA-12309 & 186 & -25.8 & $11,680 \pm 85$ & \\
AA-12310 & 226 & -26.2 & $13,725 \pm 135$ & \\
\hline
\end{tabular}

andicates the living shell sample collected to calculate a reservoir age to be subtracted from the other shell ages.

bIndicates pollen samples separated from paleosol sequences to provide a check for the shell sample.

We concentrated pollen from the paleosol samples collected at 226 and $186 \mathrm{~cm}$ depth, and obtained ${ }^{14} \mathrm{C}$ AMS ages of 13,725 BP (AA-12307) and 11,680 BP (AA-12306), respectively. At $226 \mathrm{~cm}$ depth, the pollen age agrees quite well with the reservoir-corrected shell aragonite age (Metodontia) within one standard deviation, but the reservoir-corrected shell age (Cathaica) from $186 \mathrm{~cm}$ depth is about $700 \mathrm{yr}$ younger than the pollen age. This shell sample contains some calcite, as indicated in X-ray diffraction patterns, and thus would be considered to give an unreliable age. Zhou et al. (1997) 
pointed out that pollen is an ideal material for dating paleosols from the Loess Plateau when it is deposited under a stable environment. Hence, a rough estimate of the deposition rate within the profile could be obtained using these pollen ages. A value of about $62 \mathrm{yr}$ per centimeter was calculated, and from this, a comparison could be made with the reservoir-corrected ages of the shells (Fig. 3). At $49 \mathrm{~cm}$, the reservoir-corrected age of sample AA-12327 (2490 $\pm 90 \mathrm{BP}$, Cathaica) is about 500 yr younger than the hypothetical age from the linear rate of deposition plot, but this can be considered acceptable. The reservoir-corrected age for sample AA-12328 at $62 \mathrm{~cm}(1030 \pm 70 \mathrm{BP}$, Cathaica) is significantly younger than the hypothetical rate of deposition plot. Since it contains calcite in the shell, this may explain the result, though the sample may also be intrusive.

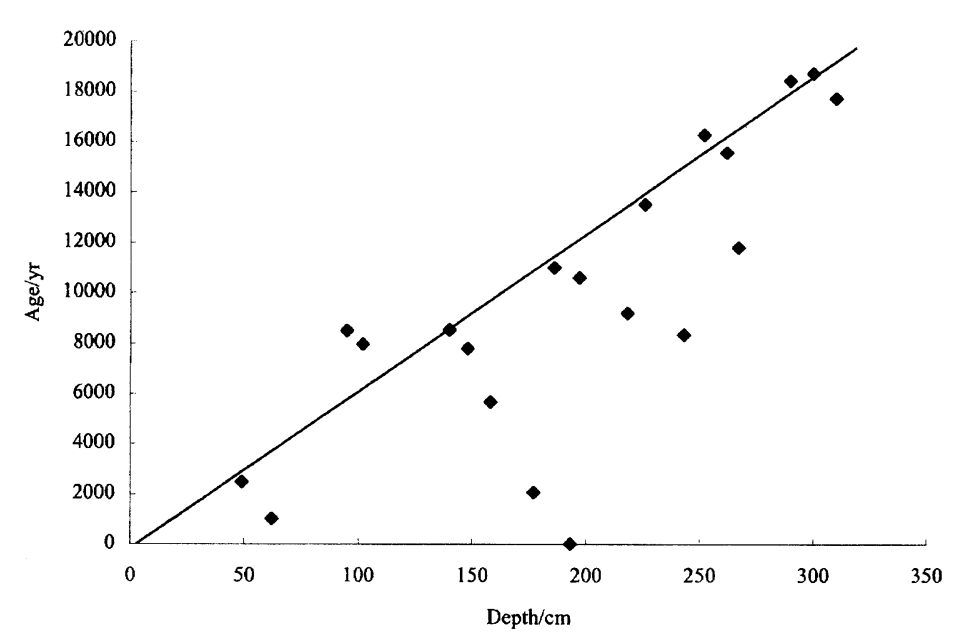

Figure 3 The Liang Cun loess-paleosol sequences. A plot of reservoir-corrected AMS ${ }^{14} \mathrm{C}$ shell ages vs. depth compared with a hypothetical rate of deposition plot using the 2 pollen dates from 186 and $226 \mathrm{~cm}$, respectively. We can see that the majority of the reservoir-corrected shell ages are younger than the rate of deposition plot, but 9 are acceptable. These are indicated in Figure 1B. The majority of the acceptable reservoircorrected shell ages are from the species Metodontia.

An approximate age of $8650 \mathrm{BP}$ was obtained from the linear rate of deposition plot for the bottom of the paleosol at $140 \mathrm{~cm}$, and $6300 \mathrm{BP}$ for the top of the paleosol at $102 \mathrm{~cm}$. Samples AA-12329 ( $95 \mathrm{~cm}, 8510 \pm 90 \mathrm{BP}$, Cathaica), AA-12330 (102 cm, $7980 \pm 90 \mathrm{BP}$, Cathaica) and AA-12331 (140 $\mathrm{cm}, 8510 \pm 120 \mathrm{BP}$, Metodontia), all yield somewhat similar reservoir-corrected ages, giving the impression that some mixing caused by bioturbation may have occurred while the soil was being formed. At $95 \mathrm{~cm}$, the hypothetical age from the deposition rate is approximately $5870 \mathrm{BP}$. This gives the impression that this paleosol may extend deeper than was previously thought (to $95 \mathrm{~cm}$ rather than $102 \mathrm{~cm}$ ). It is interesting to note that the Metodontia species is found at $140 \mathrm{~cm}$, while Cathaica species is found at the top of the paleosol, possibly indicating that warmer conditions were in place when the Metodontia shells were living, while the Cathaica species started populating the soil when the colder climate began to predominate. This possibly means that the onset of warmer conditions at this site predates the Metodontia shell age of $8540 \pm 120 \mathrm{BP}$ (reservoir corrected).

From 140 to $186 \mathrm{~cm}$, samples AA-12332 (148 cm, $7810 \pm 90 \mathrm{BP}$, Cathaica $)$, AA-12333 (158 cm, $5680 \pm 80 \mathrm{BP}$, Cathaica), and AA-12334 (177 cm, $2090 \pm 70 \mathrm{BP}$, Cathaica) give reservoir-corrected ages that do not fit the hypothetical age from the rate of deposition plot, and are too young for the rest of the sequence. There is a strong possibility that these samples are intrusive. At $186 \mathrm{~cm}$, a 
weakly developed paleosol yields a shell reservoir-corrected age of 11,000 \pm 110 BP (AA-12335, Cathaica), which is significantly younger $\left(680{ }^{14} \mathrm{C}\right.$ yr) than the pollen age from this depth, but calcite is in the shells, and recrystallization may explain this age discrepancy.

The samples at $193 \mathrm{~cm}$ (AA-12336, $30 \pm 60 \mathrm{BP}$, Cathaica), $197 \mathrm{~cm}$ (AA-12337, 10,160 $\pm 130 \mathrm{BP}$, Cathaica), and $218 \mathrm{~cm}$ (AA-12338, $9200 \pm 130 \mathrm{BP}$, Cathaica), all give reservoir-corrected ages that are far too young, and the samples could be considered to be intrusive to the profile, rather than being affected by recrystallization. At $226 \mathrm{~cm}$, the shell sample AA-12339 gives a reservoir-corrected age $(13,520 \pm 210 \mathrm{BP}$, Metodontia) that is in close agreement with the pollen age from the same level (AA-12310, 13,725 $\pm 135 \mathrm{BP}$ ). The samples collected from 252 and $262 \mathrm{~cm}$ (AA-12341, $16,270 \pm 160 \mathrm{BP}$, Cathaica and AA-12342, 15,555 $\pm 135 \mathrm{BP}$, Cathaica) give reservoir-corrected ages that straddle the hypothetical plot obtained from extrapolating the rate of deposition data obtained from the 2 pollen ages. The samples at 243 and $267 \mathrm{~cm}$ (Cathaica), give both AMS results and reservoir-corrected ages that seem too young.

The other 3 samples that could be considered to yield reliable ${ }^{14} \mathrm{C}$ ages from the reservoir-corrected values are AA-12344 (18,430 \pm 170 BP, Metodontia), AA-12345 (18,720 \pm 210 BP, Metodontia), and AA-12346 (17,720 \pm 190 BP, Metodontia). Samples AA-12344 and AA-12345 were collected within $7 \mathrm{~cm}$ of each other, so the results may be reflecting bioturbation and mixing within the sediment. Also, from rough deposition rates, the loess at $300 \mathrm{~cm}$ depth gives an approximate age of $18,530 \mathrm{BP}$. At this level, possible bioturbation may indicate the presence of loess reworking. The presence of the Metodontia species of shells also possibly indicates the onset of warmer conditions, and the chronology suggests that this section of the profile represents warmer conditions occurring as climatic conditions become less harsh after the last Glacial maximum.

We cannot assume that the anomalous ages for many of the snail shell samples collected down the profile are caused purely by recrystallization effects, as age differences are far too great. Rat burrowing, much in evidence at the site, could have transported the snails into the profile. This phenomenon seems to be associated with the Cathaica species. Certainly, the shells seem to be intrusive, and no definite explanation is forthcoming at this stage. Since the living shell species used to calculate a shell reservoir age was Cathaica, and reservoir-corrected Metodontia ages seem to fit the hypothetical rate of deposition plot quite well, one of these showing good agreement with a pollen age from the same profile depth, it is reasonable to assume that the reservoir effect calculated for the Cathaica species also applies to the Metodontia species (Table 2).

\section{CONCLUSION}

Freshwater molluscs collected from Ang Ren Lake indicate that they can be considered to be viable dating materials, provided that only aragonite is used for dating. Living shell samples of the same species seem to provide a reasonable estimate of the possible apparent age of most of the fossil shells collected from this site when the ${ }^{14} \mathrm{C}$ atmospheric concentration for the period spanning the age range of the living shells, compared with the modern standard, is actually used as the modern standard. Certainly, a reservoir correction factor obtained in this way provides a more feasible chronology than the uncorrected conventional ${ }^{14} \mathrm{C}$ AMS ages, and they fit in a reasonable sequence with a wood cellulose age from material collected $398 \mathrm{~cm}$ down the profile.

The reservoir-corrected ages also provide a chronology that fits reasonably well with evidence of climatic changes obtained elsewhere. The age of the wood cellulose fits well with the accepted age of the onset of warmer conditions after the Younger Dryas period. The approximate age of $5500 \mathrm{BP}$ for the bottom of the gravel layer at the top of the profile also fits well with a similar age found else- 
where for the onset of cold, dry conditions. The only anomalous age for a shell sample in the sequence is directly above the peat layer, and can be related to it. Obviously, this sample has been associated with different climatic conditions, and a different reservoir correction would apply.

Dating terrestrial shells from a loess profile sequence such as Liang Cun possibly can be considered viable if modern shell ${ }^{14} \mathrm{C}$ data are available to estimate a reservoir effect, as indicated above, and if the shell consists only of aragonite. Ideally, only one species of shell should be used, but in this site, the reservoir age calculated for the Cathaica species seems to apply to the Metodontia species as well. The poor development of the paleosols within the sequence at this site could be the main reason that variable reservoir effects do not seem to occur for the different shell species. A representative number of reservoir-corrected ages for both species tentatively fit a hypothetical rate-of-deposition plot even though there are many outliers. Since the majority of the reservoir-corrected shell ages are too young, this fits the assumption that both recrystallization and intrusion into the profile have occurred.

The weakly developed paleosol at $102-140 \mathrm{~cm}$ seems to give reservoir-corrected ages that are younger than a paleosol sequence that should be of similar age from the nearby Bei Zhuang Cun profile (Head et al. 1989; Zhou et al. 1990). The bottom paleosol of the Bei Zhuang sequence dated from 9600 to 8000 BP. However, since the level at $102-140 \mathrm{~cm}$ at Liang Cun shows mixing and reworking, the indicated reservoir-corrected age of $8610 \pm 120$ BP for the bottom of the profile cannot be considered representative of the true age. The reservoir-corrected ages at around $300 \mathrm{~cm}$ seem to be associated with loess reworking, and since they are from the Metodontia species, may indicate a slight warming period. This ties in with the beginning of change from glacial conditions expected during this time range.

Reservoir-corrected ages from ${ }^{14} \mathrm{C}$ concentrations of living species of snail shells from the Loess Plateau seem to provide a working chronology for the site studied, provided that they can be checked against ${ }^{14} \mathrm{C}$ ages obtained from other materials. The Metodontia species apparently provides much more reliable dating material than the Cathaica, which seems more susceptible to recrystallization.

\section{ACKNOWLEDGMENTS}

This study was supported by NSFC, 49725308 and 49894170; CAS, KZ-951-A1-402 and KZ-952S1-419; SSTC 95-40, and the US National Science Foundation (Grant EAR 95-08413). We thank an anonymous reviewer for providing constructive advice.

\section{REFERENCES}

Donahue DJ, Jull AJT, Toolin LJ. 1990. Radiocarbon measurements at the University of Arizona AMS Facility. Nuclear Instruments and Methods in Physics Research B52:224-8.

Goodfriend GA. 1987. Radiocarbon age anomalies in shell carbonate of land snails from semi-arid areas. Radiocarbon 29(2):159-68.

Head MJ. 1991. The radiocarbon dating of fresh water and marine shells. In: Gillespie R, editor. Proceedings of the Quaternary Dating Workshop 1990. Canberra: Australian National University. p 16-18.

Head MJ, Zhou W, Zhou M. 1989. Evaluation of the ${ }^{14} \mathrm{C}$ ages of organic fractions from loess-paleosol sequences near Xian, China. Radiocarbon 31(3):680 94.

Liu Tungsheng et al. 1985. Loess and the environment. Beijing: China Ocean Press. p 73-83.
Slota PJ Jr, Jull AJT, Linick TW, Toolin LJ. 1987. Preparation of small samples for ${ }^{14} \mathrm{C}$ accelerator targets by catalytic reduction of CO. Radiocarbon 29(2):303-6.

Spennemann DHR, Head MJ. 1996. Reservoir modification of radiocarbon signatures in coastal and nearshore waters of Eastern Australia: the state of play. Quaternary Australasia 14(1):32-9.

Stuiver M, Polach HA. 1977. Discussion: reporting of ${ }^{14} \mathrm{C}$ data. Radiocarbon 19(3):355-63.

Zhou WJ, Donahue DJ, Jull AJT. 1997. ${ }^{14} \mathrm{C}$ AMS dating of pollen from aeolian sand palaeosol and peat samples: implications for rapid climate change in the late Quaternary. Radiocarbon 39(1):19-26.

Zhou WJ, Zhou MF, Head MJ. 1990. ${ }^{14} \mathrm{C}$ chronology of Bei Zhuang Cun sedimentation sequences since 30,000 years BP. Chinese Science Bulletin 35(7):56772. 